\title{
Yr58: A New Stripe Rust Resistance Gene and Its Interaction with Yr46 for Enhanced Resistance
}

\author{
Mumta Chhetri, Harbans Bariana, Pakeerathan Kandiah, and Urmil Bansal
}

All authors: University of Sydney Plant Breeding Institute-Cobbitty, Faculty of Agriculture and Environment, PMB 4011, Narellan, NSW2567, Australia.

Accepted for publication 10 July 2016.

\begin{abstract}
Chhetri, M., Bariana, H., Kandiah, P., and Bansal, U. 2016. Yr58: A new stripe rust resistance gene and its interaction with $\mathrm{Yr} 46$ for enhanced resistance. Phytopathology 106:1530-1534.

The quantitative trait loci $Q Y$ r.sun- $3 B S$ and $Q Y$ r.sun- $4 D L$ were identified in the W195/BTSS recombinant inbred line (RIL) population in a previous study. QYr.sun-3BS explained 34 to 59\% phenotypic variation in stripe rust response. We evaluated parental genotypes at different growth stages and temperature regimes to detect the critical stage for expression of QYr.sun$3 B S$. W195 expressed low infection type (IT) ;1C at the fourth leaf stage,

was temporarily named $\mathrm{YrW195}$. YrW195 corresponded to QYr.sun-3BS. Since no previously designated stripe rust resistance genes that expresses at and after the fourth leaf stage was mapped in this region, $\mathrm{YrW195}$ was formally named $Y r 58$. Genotyping with $Y r 46$-linked markers indicated the presence of Yr46 in W195, which corresponded to QYr.sun-4DL. The RILs carrying $Y r 58$ and $Y r 46$ singly produced IT $23 \mathrm{C}$ and IT $3^{+}$, respectively, and those carrying both genes produced IT ; $1 \mathrm{C}$ indicating the enhancement of Yr58 expression by $Y r 46$. The absence of $Y r 58$-linked alleles of markers sun533 and sun 476 in 74 of the 76 wheat cultivars demonstrated their usefulness for marker-assisted selection.
\end{abstract} when incubated at $21 \pm 2^{\circ} \mathrm{C}$ and the alternate parent BTSS was susceptible $\left(\right.$ IT $3^{+}$). Monogenic segregation for stripe rust response was observed among the RIL population at the fourth leaf stage and the underlying locus
Additional keywords: DArTseq markers, genome survey sequences, single nucleotide polymorphism markers, stripe (yellow) rust, Triticum aestivum.
Stripe rust, caused by Puccinia striiformis f. sp. tritici, is the foremost biotic constraint of wheat production in Australia and is estimated to incur an annual average loss of Australian $\$ 127 \mathrm{~m}$ (Murray and Brennan 2009). Australia was free from this disease until its detection in 1979 in the eastern Australian wheat belt (O'Brien et al. 1980). It is believed to have originated from Europe and the pathotype was typed as 104 E137A-. Another significant introduction of stripe rust was noted in Western Australia in 2002 and was typed as 134 E16A+ (Wellings et al. 2003). This pathotype evolved to acquire virulence for resistance genes $Y r 10, Y r 17, Y r 24, Y r 27$, and $Y r 17+Y r 27$. In addition, virulence for a stripe rust resistance gene, $Y r J$, present in the triticale cultivar Jackie, was detected and the derivative was named $134 \mathrm{E} 16 \mathrm{~A}+\mathrm{J}+$. Two variants of this pathotype, $134 \mathrm{E} 16 \mathrm{~A}+\mathrm{J}+Y r 27+$ and $134 \mathrm{E} 16 \mathrm{~A}+\mathrm{J}+\mathrm{T}+$, with additional virulence for $Y r 27$ and $Y r T$ (gene in triticale cultivar Tobruk), respectively, were identified. While several genes were rendered ineffective by the pathotype 134 E16A+ and its derivatives, stripe rust resistance genes $\mathrm{Yr} 3$ and $\mathrm{Yr} 4$ present in the European wheat germplasm remained effective (Wellings 2007). Bariana et al. (2006) identified a stripe rust gene in a Western Australian advanced breeding line WAWHT2046 and named it $Y r 34$. Like $Y r 3$ and $Y r 4, Y r 34$ remained effective against all variants of the pathotype $134 \mathrm{E} 16 \mathrm{~A}+$, despite its ineffectiveness against the pre-2002 P. striiformis f. sp. tritici pathotypes.

Deployment of diverse combinations of resistance genes is the most economical way to combat evolution of virulence in the stripe rust pathogen. Characterization of new sources of resistance is therefore essential. The wheat genotype W195 showed high level of resistance against $134 \mathrm{E} 16 \mathrm{~A}+$ and its derivatives detected so far and the involvement of chromosomes 3BS (QYr.sun-3BS) and 4DL

Corresponding author: U. Bansal; E-mail address: urmil.bansal@sydney.edu.au

http://dx.doi.org/10.1094/PHYTO-04-16-0182-R

(C) 2016 The American Phytopathological Society
(QYr.sun-4DL) in controlling stripe rust resistance in W195 was demonstrated (Chhetri et al. 2016). These quantitative trait loci (QTL) explained 34.1 to $59.2 \%$ and 11.0 to $22.6 \%$ of the phenotypic variation in stripe rust response, respectively. This investigation was planned to Mendelize these QTL, develop closely linked markers, and validate linked markers.

\section{MATERIALS AND METHODS}

Plant material. Spring wheat genotype W195, a landrace from India, was crossed with a selection from BT-Schomburgk (Halberd/ Aroona//3*Shomburgk), a South Australian boron tolerant wheat cultivar released in 1994, referred to as BTSS, to generate an $\mathrm{F}_{6: 7}$ recombinant inbred line (RIL) population ( 88 RILs). The population enhancement details are described in Chhetri et al. (2016). This $\mathrm{F}_{6: 7}$ W195/BTSS RIL population was used to Mendelize QYr.sun-3BS and QYr.sun-4DL. Seventy-six Australian common wheat cultivars were used as a validation panel to test the robustness of markers closely linked with QYr.sun-3BS.

Stripe rust tests in greenhouse. Six sets of W195, BTSS, and the susceptible cultivar Morocco (eight seeds per pot) were sown in $9 \mathrm{~cm}$ plastic pots filled with a mixture of pine bark and river sand at a 2:1 ratio to raise seedlings for greenhouse tests. Water soluble fertilizer Aquasol (10 g/10 liters of water) was applied to pots before sowing. One application each of urea at the same rate as Aquasol was performed 7 days after sowing and at the time of inoculation. Plants were inoculated with $P$. striiformis f. sp. tritici pathotype 134 E16A+ $Y r 17+Y r 27+(617)$ at the second, third, and fourth leaf stages. Inoculations were carried out by misting urediniospores suspended in light mineral oil (Isopar L, $5 \mathrm{mg}$ of spores per $10 \mathrm{ml}$ ) using a hydrocarbon pressure pack. Inoculated seedlings were then incubated for $24 \mathrm{~h}$ at 9 to $11^{\circ} \mathrm{C}$ in a dark room on water-filled steel trays covered with plastic hoods to create $100 \%$ humidity. Single sets of seedlings inoculated at the second, third, and fourth leaf stages were then moved to microclimate rooms maintained at $17 \pm 2^{\circ} \mathrm{C}$ and $21 \pm 2^{\circ} \mathrm{C}$. 
Rust response assessments were made 14 to 16 days postinoculation on the 0 to 4 scale described in Bariana and McIntosh (1993). More than usual necrosis or chlorosis was denoted by letters ' $\mathrm{N}$ ' and ' $\mathrm{C}$ ', respectively.

Parental genotypes (W195 and BTSS) were also evaluated against $P$. striiformis f. sp. tritici pathotypes $134 \mathrm{E} 16 \mathrm{~A}+(572), 134$ $\mathrm{E} 16 \mathrm{~A}+Y r 17+(599), 134 \mathrm{E} 16 \mathrm{~A}+\mathrm{J}+Y r 27+(607), 134 \mathrm{E} 16 \mathrm{~A}+\mathrm{J}+\mathrm{T}+$ (615), and $150 \mathrm{E} 16 \mathrm{~A}+(598)$ at the fourth leaf stage using the abovementioned procedure to assess stripe rust responses.

The W195/BTSS RIL population and the parental genotypes were sown in four lines per pot (six seeds per RIL) using the abovementioned procedure and inoculated at the fourth leaf stage with P. striiformis f. sp. tritici pathotype $134 \mathrm{E} 16 \mathrm{~A}+\mathrm{Yr} 17+Y r 27+$ and incubated at $21 \pm 2{ }^{\circ} \mathrm{C}$. The experiment was conducted in three replications.

Adult plant stripe rust tests in field. Adult plant stripe rust response data on the W195/BTSS RIL population from Chhetri et al. (2016) were used to assess the interaction of QYr.sun-3BS and QYr.sun-4DL.

DNA isolation and molecular genotyping. Genomic DNA from the RIL population, parents (W195 and BTSS), and Australian cultivars was extracted following the procedure described in Bansal et al. (2014a).

Saturation of QYr.sun-3BS region. DArTseq markers (sequences 30 to $40 \mathrm{bp}$ ) closely linked to QYr.sun-3BS (Chhetri et al. 2016) were subjected to BLAST search (http://www.wheatgenome. org/) against wheat genome survey sequence (GSS) and $>5 \mathrm{~KB}$ contigs were identified. These contigs were then screened for di-, tri, tetra-, penta-, and hexa-nucleotide repeats (Table 1) using the simple sequence repeat (SSR) IT Tool (http://archive.gramene. org/db/markers/ssrtool) and primers were designed using the Primer3 software (Rozen and Skaletsky 1999; http://primer3. sourceforge.net/). Eight SSR markers were designed (Table 2) from the DArTseq sequences and primers were designated as 'sun' (Sydney University). These sun markers and 14 SSR markers (barc75, barc92, barc157, barc180, barc147, cfd79, gwm493, gwm389, cfb3417, cfb3530, cfb5006, cfb5007, cfb5008, and cfb5010) previously mapped on chromosome arm 3BS (Dieguez et al. 2014; Somers et al. 2004; http://wheat.pw.usda.gov) were genotyped on parents and bulks. The PCR was performed in $10 \mu \mathrm{l}$ volume containing $60 \mathrm{ng}$ of DNA, $1 \times$ PCR buffer containing $1.5 \mathrm{mM} \mathrm{MgCl} 2,200 \mathrm{mM}$ of dNTPs, $50 \mathrm{nM}$ of M13 labeled forward primer and $100 \mathrm{nM}$ reverse primer, $50 \mathrm{nM}$ of IR700/IR800 fluorescent tag labeled with M13, and 0.2 units of Immolase DNA polymerase (Bioline, Australia). Electrophoresis of PCR products was carried out in $2.5 \%$ agarose gel (Amresco) stained with GelRed and 1-kb ladder was used to determine the allele sizes. Amplicons that could not be discriminated in agarose gel were electrophoresed in $6.5 \%$ polyacrylamide gel using DNA Analyzer (LI-COR-4300 Biosciences) according to Bansal et al. (2014b).

Genotyping with gene-linked markers. Lr67/Yr46-linked single nucleotide polymorphism (SNP) marker csSNP856 (Forrest et al. 2014) was tested on the entire W195/BTSS RIL population. Reactions were performed using a 96-well PCR plate in CFX96 Real-Time PCR detection system (Bio-Rad). The 8 - $\mu$ l reaction volume contained $4 \mu \mathrm{l}$ of $2 \times$ KASP mix (LGC Genomics, UK), $0.11 \mu \mathrm{l}$ of primer mix (containing $12 \mu \mathrm{M}$ each allele-specific forward primer and $30 \mu \mathrm{M}$ of reverse primer), $3 \mu \mathrm{l}$ of genomic DNA
(30 ng/ $\mu \mathrm{l}$ ), and $0.89 \mu \mathrm{l}$ of autoclaved $\mathrm{ddH}_{2} \mathrm{O}$. The following cycling conditions were used: $15 \mathrm{~min}$ at $94^{\circ} \mathrm{C} ; 10$ touchdown cycles of $20 \mathrm{~s}$ at $94^{\circ} \mathrm{C}, 60 \mathrm{~s}$ at 65 to $57^{\circ} \mathrm{C}$ (dropping $0.8^{\circ} \mathrm{C}$ per cycle); and 26 to 35 cycles of $20 \mathrm{~s}$ at $94^{\circ} \mathrm{C}$ and $60 \mathrm{~s}$ at $57^{\circ} \mathrm{C}$. Reading was taken by fluorescence detection of the reactions at $40^{\circ} \mathrm{C}$ for $30 \mathrm{~s}$ and the data were analyzed using allele discrimination software.

Markers gwm533 (Spielmeyer et al. 2003) and csSr2 (Mago et al. 2011) linked with the adult plant stem rust resistance gene $S r 2$ were also genotyped on the entire W195/BTSS RIL population.

Data analysis. The phenotypic and genotypic data of the W195/ BTSS RIL population were subjected to $\chi^{2}$ analysis to detect segregation distortion. Genetic linkage maps were constructed using QTXb20 version 3.0 (Manly et al. 2001) software. Recombination fractions were converted to centi-Morgans (cM) by applying Kosambi map function (Kosambi 1943). Ultimate map figures were prepared using MapChart software (Voorrips 2002).

\section{RESULTS}

Greenhouse stripe rust tests. $Q Y$ r.sun- $3 B S$ was detected at a very high LOD score based on the adult plant stripe rust response variation among the RILs under field conditions (Chhetri et al. 2016). W195 expressed a high level of resistance at the tillering stage in all field experiments ( 3 on a 1 to 9 scale). These observations prompted us to conduct, greenhouse tests at different growth stages (second, third, and fourth leaf) and postinoculation temperature regimes $\left(17 \pm 2^{\circ} \mathrm{C}\right.$ and $\left.21 \pm 2^{\circ} \mathrm{C}\right)$ for detailed characterization of QYr.sun-3BS. The higher than usual postinoculation temperature $\left(21 \pm 2^{\circ} \mathrm{C}\right)$ for seedling stripe rust tests was chosen to assess the role of high temperature in expression of resistance under the greenhouse conditions. Initial tests were performed only on W195, BTSS, and the susceptible control Morocco. Parental genotypes W195 and BTSS showed susceptible responses against $P$. striiformis f. sp. tritici pathotype 134 E16A+ Yr17+Yr27+ at the second and third leaf stages under greenhouse

TABLE 2. Sequence of closely linked simple sequence repeat (SSR) markers derived from genome survey sequence (GSS) contigs ${ }^{\mathrm{a}}$

\begin{tabular}{|c|c|c|c|c|}
\hline $\begin{array}{l}\text { SSR } \\
\text { marker }\end{array}$ & $\begin{array}{c}\text { GSS } \\
\text { contig }\end{array}$ & $\begin{array}{l}\text { Repeat } \\
\text { motif }\end{array}$ & $\begin{array}{l}\text { Primer } \\
\text { identifier }\end{array}$ & $\begin{array}{l}\text { Primer sequence* } \\
\qquad\left(5^{\prime}-3^{\prime}\right)\end{array}$ \\
\hline sun637 & 10474890M & (TGA)4 & $\begin{array}{l}\text { Forward } \\
\text { Reverse }\end{array}$ & $\begin{array}{l}\text { ttcggttacttgtgtgcttat } \\
\text { aagcatcatcacaatcaacat }\end{array}$ \\
\hline sun641 & $10761727 \mathrm{P}$ & (CTG)4 & $\begin{array}{l}\text { Forward } \\
\text { Reverse }\end{array}$ & $\begin{array}{l}\text { cgaagctcatgattaaatacg } \\
\text { cgattgttaattgctcagagt }\end{array}$ \\
\hline sun533 & $10765289 \mathrm{P}$ & $(\mathrm{CGC}) 3$ & $\begin{array}{l}\text { Forward } \\
\text { Reverse }\end{array}$ & $\begin{array}{l}\text { catcctcctccttactgc } \\
\text { ggaagaaccaagaggatttac }\end{array}$ \\
\hline sun 474 & $10598800 \mathrm{P}$ & $(\mathrm{AGC}) 5$ & $\begin{array}{l}\text { Forward } \\
\text { Reverse }\end{array}$ & $\begin{array}{l}\text { tgccatataaacacaacaatg } \\
\text { tatatttagcgctagctcctg }\end{array}$ \\
\hline sun639 & $10598800 \mathrm{M}$ & $(\mathrm{GCC}) 4$ & $\begin{array}{l}\text { Forward } \\
\text { Reverse }\end{array}$ & $\begin{array}{l}\text { acacgcacaagaaggaga } \\
\text { gaatgctagctagagcctga }\end{array}$ \\
\hline sun640 & $10598800 \mathrm{M}$ & $(\mathrm{CAG}) 4$ & $\begin{array}{l}\text { Forward } \\
\text { Reverse }\end{array}$ & $\begin{array}{l}\text { cttgactttgaccaaacctta } \\
\text { cagctaccgaattaaagaaca }\end{array}$ \\
\hline sun 476 & $10516868 \mathrm{P}$ & $(\mathrm{GCT}) 4$ & $\begin{array}{l}\text { Forward } \\
\text { Reverse }\end{array}$ & $\begin{array}{l}\text { actcgectccgtatatacatt } \\
\text { atttgagcttccttctcatt }\end{array}$ \\
\hline sun638 & $10516868 \mathrm{M}$ & $(\mathrm{GGC}) 4$ & $\begin{array}{l}\text { Forward } \\
\text { Reverse }\end{array}$ & $\begin{array}{l}\text { acgaatccttcctatcacact } \\
\text { gaaaccaaatcgacagagaa }\end{array}$ \\
\hline
\end{tabular}

a * Indicates M13 seq: CACGACGTTGTAAAACGAC attached at 5' end of forward primers.

TABLE 1. DArTseq markers sequences with corresponding genome survey sequence (GSS) contig numbers and repeat motifs (http://www.wheatgenome.org/)

\begin{tabular}{|c|c|c|c|}
\hline DArTseq marker & Marker sequence & GSS contig & Repeat motif \\
\hline 1106533 & tgcagaatcgcactttcttaaaagaatgaaacttttctgcaactcaactggtcaattgcggctccaagt & 10474890 & (TGA)4 \\
\hline 3023704 & tgcagaagcgtgaggaacgagtaatcagctctgtttcgatgccgagatcggaagagcggttcagcagga & 10761727 & $(\mathrm{CTG}) 4$ \\
\hline 100016328 & tgcagcacccaaatgttctgagtgaggcagtcaccgagatcggaagaacggttcagcaggaatgccgag & 10765289 & $(\mathrm{CGC}) 3$ \\
\hline 1233292 & tgcaggcacgtaccgtgccatgtaaaactagctggccatggtgaaaagaggcatcgccaagacacacct & 10598800 & $(\mathrm{AGC}) 5 /(\mathrm{GCC}) 4 /(\mathrm{CAG}) 4$ \\
\hline 1217990 & tgcagcagccgcgtcttcttcatgagctcctccttgagcctgctgttctcctgcaactagggtgagaga & 10516868 & (GGC)4/(GCT)4 \\
\hline
\end{tabular}


conditions following incubation at $17 \pm 2^{\circ} \mathrm{C}$. W195 produced infection type (IT) $23 \mathrm{C}$ at the fourth leaf stage (Fig. 1A) under $17 \pm$ $2{ }^{\circ} \mathrm{C}$ temperature and IT $; 1 \mathrm{C}$ at $21 \pm 2{ }^{\circ} \mathrm{C}$ (Fig. 1B). In contrast, the alternate parent BTSS produced susceptible response (IT $3^{+}$) at both temperature regimes. W195 exhibited resistance against all current derivatives of $134 \mathrm{E} 16 \mathrm{~A}+[134 \mathrm{E} 16 \mathrm{~A}+(572), 134 \mathrm{E} 16 \mathrm{~A}+\mathrm{Yr} 17+$ (599), $134 \mathrm{E} 16 \mathrm{~A}+\mathrm{J}+Y r 27+(607), 134 \mathrm{E} 16 \mathrm{~A}+\mathrm{J}+\mathrm{T}+(615)$, and 150 $\mathrm{E} 16 \mathrm{~A}+(598)]$ at the fourth leaf stage.

The entire W195/BTSS RIL population was screened against P. striiformis f. sp. tritici pathotype $134 \mathrm{E} 16 \mathrm{~A}+Y r 17+Y r 27+$ at the fourth leaf stage at $21 \pm 2{ }^{\circ} \mathrm{C}$ postincubation temperature. Forty-nine RILs produced ITs ; $1 \mathrm{C}$ to $23 \mathrm{C}$ and 39 RILs were scored as susceptible (IT $3^{+}$) (Table 3 ). $\chi^{2}$ analysis of phenotypic data resulted in conformity to monogenic segregation for stripe rust response at the fourth leaf stage. The underlying stripe rust resistance locus was tentatively named $\mathrm{YrW195.}$

Molecular mapping of $\mathbf{Y r W 1 9 5}$. The stripe rust response data of W195/BTSS RIL population was converted into genotypes and incorporated into the DArTseq map (Chhetri et al. 2016). $\mathrm{YrW195}$ mapped in the marker interval 3023704-100016328, where $Q Y r$. sun-3BS peaked in QTL analysis (Chhetri et al. 2016). These results led to the conclusion that QYr.sun-3BS and $\mathrm{YrW195}$ are the same.

To saturate the $\mathrm{YrW195}$ region, five closely linked DArTseq marker sequences $(106533,3023704,100016328,1233292$, and 1217990 ) were blasted against the wheat genome survey sequence and five survey sequence scaffolds (10474890, 10761727, 10765289, 10598800, and 10516868) were identified (Table 2). Eight SSR markers were designed and were tested on parental genotypes W195 and BTSS. Four markers (sun474, sun476, sun533 and sun641) were polymorphic between parents. Marker sun641 and sun 474 were dominant and did not produce any amplicon in W195, whereas sun476 and sun533 were codominant. Markers sun476 and sun533 were evaluated on the entire W195/BTSS RIL population. Primer sequences are given in Table 2. In addition, 2 out of
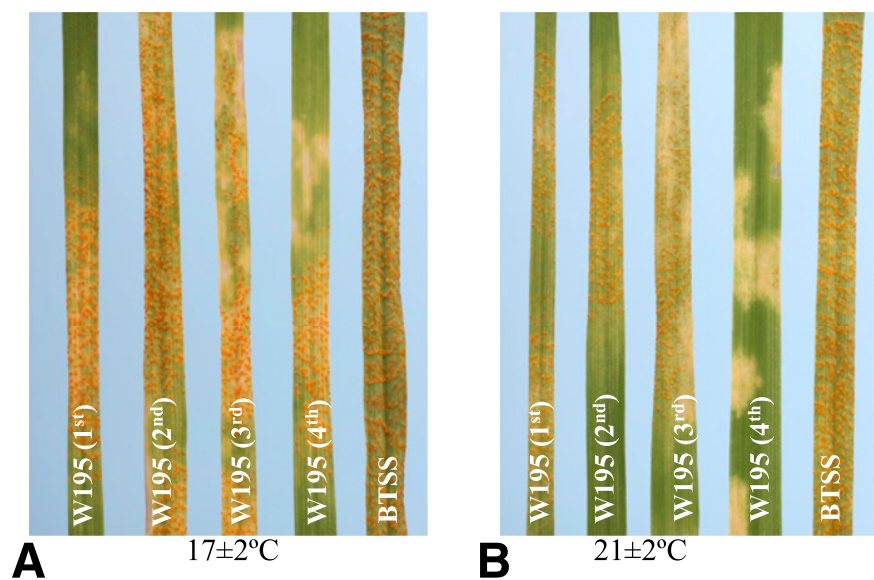

Fig. 1. Stripe rust responses produced by W195 and BTSS, when tested against Puccinia striiformis f. sp. tritici pathotype $134 \mathrm{E} 16 \mathrm{~A}+Y r 17+Y r 27$ at the different growth stages $\mathbf{A}, 17 \pm 2{ }^{\circ} \mathrm{C}$ and $\mathbf{B}, 21 \pm 2^{\circ} \mathrm{C}$ postincubation temperature.

TABLE 3. Distribution of W195/BTSS recombinant inbred line population, when tested with Puccinia striiformis f. sp. tritici pathotype 134 E16A+Yr17+ Yr27 at the fourth leaf stage at $21 \pm 2{ }^{\circ} \mathrm{C}$ postincubation temperature ${ }^{\mathrm{a}}$

\begin{tabular}{lccc}
\hline & \multicolumn{2}{c}{ Number of lines } & \\
\cline { 2 - 3 } Stripe rust response (infection type) & Observed & Expected & $\chi^{2}(1: 1)$ \\
\hline Homozygous resistant (;1 N to 23C) & 49 & 44 & 0.57 \\
Homozygous susceptible (3+) & 39 & 44 & 0.57 \\
Total & 88 & 88 & 1.14 \\
\hline
\end{tabular}

${ }^{\text {a }} \chi^{2}$ at $P=0.05$ is 3.84 and $P=0.01$ is 6.64 at $1 \mathrm{df}$.
14 polymorphic SSR markers (gwm389 and barc75) previously located on chromosome arm 3BS (Somers et al. 2004; http://wheat.pw. usda.gov) that showed polymorphism between parents, were also genotyped on the entire RIL population. Genetic linkage map of the YrW195 was constructed including seven DArTseq markers (1112443, $2275344,3023704,1130043,1115466,1373089$, and 1372435) and four SSR markers (barc75, gwm389, sun476, and sun533). SSR markers sun 476 and sun 533 mapped $0.6 \mathrm{cM}$ proximal and DArTseq marker 3023704 mapped $1.2 \mathrm{cM}$ distal to $\mathrm{YrW195}$ (Fig. 2A).

Genotyping with $\mathbf{S r}$-linked marker. Sr2-linked markers; csSr2 was monomorphic between the parents, whereas gwm533 was polymorphic and it mapped $5.3 \mathrm{cM}$ proximal to $\mathrm{YrW} 195$ (Fig. 2A).

Genotyping with $Y$ r46-linked marker. The adult plant stripe rust resistance gene $\mathrm{Yr} 46$ was located on chromosome arm 4DL (Herrera-Foessel et al. 2011). Yr46-linked SNP marker csSNP856 was polymorphic between the parents W195 and BTSS and it was genotyped on all RILs. The $c s S N P 856$ genotypic data were incorporated in the W195/BTSS linkage map and it mapped $1.2 \mathrm{cM}$ distal to the DArTseq marker 1052292, where QYr.sun-4DL peaked (Chhetri et al. 2016). The final linkage map of chromosome 4DL arm is depicted in Figure 2B. Based on these results, we concluded that QYr.sun- $4 D L$ and $Y r 46$ are the same.

Interaction of $\mathbf{Y r 4 6}$ and $\mathbf{Y r W 1 9 5}$. The W195/BTSS RILs were classified for the presence or absence of $Y r 46$ and $Y r W 195$ based the Yr46-linked marker csSNP856 and the fourth leaf greenhouse phenotype, respectively (Table 4). RILs carrying the combination of both genes (YrW195YrW195Yr46Yr46) produced IT ;1C at the fourth leaf stage (Fig. 1B), whereas those carrying YrW195 singly (YrW195YrW195yr46yr46) were scored as 23C. RILs with genotypic constitutions yrW195yrW195Yr46Yr46 and yrW195yrW195yr46yr46 displayed susceptible IT $3^{+}$. These results demonstrated the enhanced expression of $\mathrm{YrW} 195$ in the presence of $\mathrm{Yr} 46$.

Validation of Yr195-linked markers. To check the usefulness of $\mathrm{YrW195}$-linked markers for marker-assisted selection, a set of 76 Australian wheat cultivars was tested with codominant PCR-based markers sun476 and sun533 (Table 5). All test cultivars amplified the susceptible parent BTSS specific alleles, except cultivars Bolac and SQP Revenue. These two cultivars displayed marker profiles similar to W195. The amplification of alternate marker alleles to that linked with $\mathrm{YrW195}$ in $97.4 \%$ of cultivars demonstrated the usefulness of these markers in marker-assisted selection of this gene in breeding programs.

\section{DISCUSSION}

This investigation was planned to characterize a major QTL ( $Q Y r$. sun-3BS) reported by Chhetri et al. (2016) in the W195/BTSS RIL population consisting of 88 RILs at different growth stages and

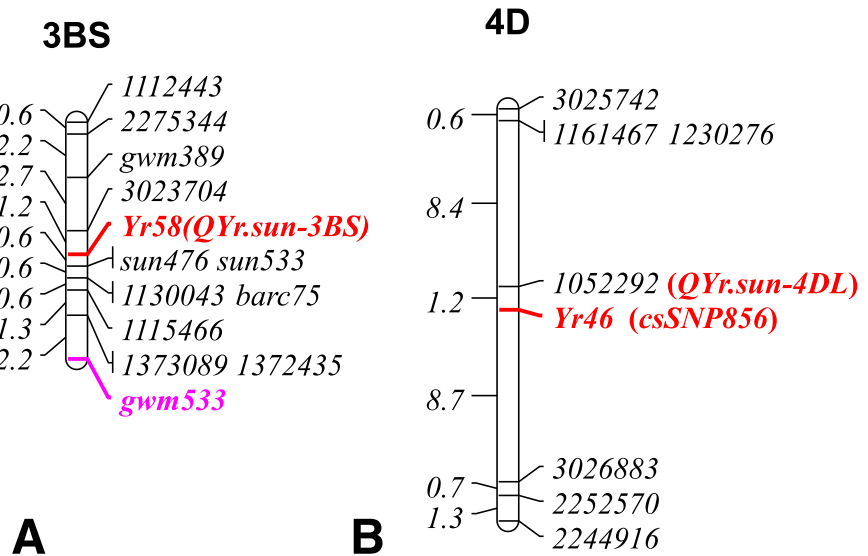

Fig. 2. Genetic map of chromosomes A, 3B and B, 4D showing locations of stripe rust resistance genes $\operatorname{Yr} 58$ and $\mathrm{Yr} 46$. 
temperature regimes under greenhouse conditions. Yang et al. (2011) used Monte Carlo simulation to compare the QTL detection in a doubled haploid population of barley using high and low density maps versus; small and large size populations. This simulation study indicated that a small population with high marker density can predict accurate QTL if the trait is highly heritable. High density map of W195/BTSS RIL population helped Chhetri et al. (2016) to identify QYr.sun-3BS and QYr.sun-4DL where stripe rust response data showed high heritability across years. Taking into consideration the phenotypic contribution of QYr.sun-3BS, we phenotyped resistant parent W195 against $P$. striiformis f. sp. tritici at different growth stages under the controlled environmental conditions (greenhouse). W195 expressed IT ;1C at the fourth leaf stage. Monogenic segregation for stripe rust response expressed at the fourth leaf stage among the W195/BTSS RIL population led to temporary naming of the underlying locus as $\mathrm{YrW195}$. In a revised QTL analysis following incorporation of $\mathrm{YrW195}$ in chromosome 3B map, QYr.sun-3BS peaked at $\operatorname{YrW195}$. Despite the small population size, these results demonstrated that QYr.sun-3BS is coincident with $\mathrm{YrW195}$. All stage resistance (ASR) genes $\mathrm{Yr}$, Yr57, and Yrwh2 were previously located on chromosome arm 3BS (Bansal et al. 2010; Randhawa et al. 2015; Zhou et al. 2014). Marker gwm389 is common in maps representing locations of Yr57 and YrW195. Based on the common marker gwm389, Yr57 (Randhawa et al. 2015) maps $5.9 \mathrm{cM}$ distal to $\operatorname{YrW195}$. Moreover, $\operatorname{Yr} 57$ is a typical ASR gene and expresses clearly at the second leaf stage in

TABLE 4. Interaction of stripe rust resistance gene $\operatorname{YrW195}$ (Yr58) with $Y r 46$ in W195/BTSS recombinant inbred line population

\begin{tabular}{lccc}
\hline Genotype $^{\mathrm{a}}$ & $\begin{array}{c}\text { YrW195YrW195 } \\
(\text { Yr58Yr58) }\end{array}$ & $\begin{array}{c}\text { yrW195yrW195 } \\
(\text { yr58yr58) }\end{array}$ & Total \\
\hline Yr46Yr46 & $22(; 1 \mathrm{~N})^{\mathrm{a}}$ & $20(3+)$ & 42 \\
yr46yr46 & $27(23 \mathrm{C})$ & $19(3+)$ & 46 \\
Total & 49 & 39 & 88 \\
\hline
\end{tabular}

a Infection type and $\chi^{2} 1: 1($ YrW195 vs. $y r W 195)=1.14, \chi^{2} 1: 1($ Yr46 vs. $y r 46)=0.18$ (table value at $P=0.05$ is 3.84 and $P=0.01$ is 6.63 at $1 \mathrm{df}$ ).

TABLE 5. Validation of Yr58-linked markers on a set of Australian cultivars

\begin{tabular}{|c|c|c|c|}
\hline Wheat genotype & $\operatorname{Yr} 58$ & $\begin{array}{l}\text { sun533 } \\
\text { (bp) }\end{array}$ & $\begin{array}{c}\text { sun476 } \\
\text { (bp) }\end{array}$ \\
\hline \multicolumn{4}{|l|}{ Parental lines } \\
\hline W195 & + & 156 & 178 \\
\hline BTSS & - & 149 & 170 \\
\hline \multicolumn{4}{|l|}{ Australian cultivars } \\
\hline \multicolumn{4}{|l|}{ AGT Katana, Axe, Baxter, Beaufort, } \\
\hline \multicolumn{4}{|l|}{ Bolac, Calingiri, Carnamah, Catalina, } \\
\hline \multicolumn{4}{|l|}{ Chara, Cobra, Corack, Correll, } \\
\hline \multicolumn{4}{|l|}{ Crusader, Dart, Derrimut, } \\
\hline \multicolumn{4}{|l|}{ Diamondbird, EGA Bonnie Rock, } \\
\hline \multicolumn{4}{|l|}{ EGA Bounty, EGA Burke, EGA } \\
\hline \multicolumn{4}{|l|}{ Gregory, EGA Wedgetail, EGA } \\
\hline \multicolumn{4}{|l|}{ Wylie, Elmore CL Plus, Emu Rock, } \\
\hline \multicolumn{4}{|l|}{ Envoy, Espada, Estoc, Forrest, } \\
\hline \multicolumn{4}{|l|}{ Fortune, Gauntlet, Gazelle, GBA } \\
\hline \multicolumn{4}{|l|}{ Sapphire, Giles, Gladius, Grenade CL } \\
\hline \multicolumn{4}{|l|}{ Plus, Impala, Impose CL Plus, Janz, } \\
\hline \multicolumn{4}{|l|}{ Justica CL Plus, King Rock, Kord CL } \\
\hline \multicolumn{4}{|l|}{ Plus, Kunjin, Lang, Lincoln, } \\
\hline \multicolumn{4}{|l|}{ Livingston, Mace, Mackellar, } \\
\hline \multicolumn{4}{|l|}{ Magenta, Merinda, Merlin, Naparoo, } \\
\hline \multicolumn{4}{|l|}{ Orion, Phantom, Preston, Scout, } \\
\hline \multicolumn{4}{|l|}{ Sentinel, Shield, Spitfire, SQP } \\
\hline \multicolumn{4}{|l|}{ Revenue, Strzelecki, Sunco, } \\
\hline \multicolumn{4}{|l|}{ Sunguard, Suntop, Sunvale, Sunvex, } \\
\hline \multicolumn{4}{|l|}{ Sunzell, Ventura, Waagan, Wallup, } \\
\hline \multicolumn{4}{|l|}{ Wedin, Westonia, Wyalkatchem, } \\
\hline Wylah, Yandanooka, Yitpi, Young & - & 149 & 170 \\
\hline Bolac, SQP Revenue & - & 156 & 178 \\
\hline
\end{tabular}

the greenhouse and is effective against both pre- and post-2002 P. striiformis f. sp. tritici pathotypes. Although both $\mathrm{Yr} 4$ and $\mathrm{YrW195}$ are not effective against the pre-2002 Australian P. striiformis f. sp. tritici pathotypes, these genes differ in their expression at the second leaf stage at $17 \pm 2^{\circ} \mathrm{C}$. The expression of Yrwh2 (Zhou et al. 2014) in the seedling stage also precludes the possibility of this gene to be $\mathrm{YrW195}$ due to expression of the latter at the fourth leaf stage. A major HTAP QTL designated as QYrAlt.syau-3BS (Zhao et al. 2012) from cultivar Alturas was located in the same region as $\mathrm{YrW195}$. Resistance in Alturas only expresses at the flowering and soft dough stages unlike the $\mathrm{YrW} 195$ resistance, which expresses at and after the fourth leaf stage. These attributes clearly demonstrate the uniqueness of $\mathrm{YrW195}$ and it was formally named $\mathrm{Yr} 58$.

Adult plant stem rust resistance gene $\mathrm{Sr} 2$ is also located in chromosome arm 3BS. In order to estimate the distance between $\mathrm{Sr} 2$ and $\mathrm{Yr} 58$, we tested Sr2-linked marker in the W195/BTSS population. Map position indicated that $\mathrm{Yr} 58$ and $S \mathrm{r} 2$ are $5.3 \mathrm{cM}$ apart and can be recombined. As $S r 2$ is linked with $L r 27$ and $Y r 30$ (McIntosh et al. 1995; Singh et al. 2000), recombinant genotypes carrying these genes in combination with $\operatorname{Yr} 58$ will also provide resistance to stem rust and leaf rust.

Markers sun476 and sun533 showed close linkage with $\operatorname{Yr} 58$ (Fig. 2A) and were validated on a set of Australian wheat cultivars. Of 76 Australian wheat cultivars 74 carried alleles different from those amplified in W195 when genotyped with Yr58-linked markers sun 476 and sun533, indicating their usefulness in markerassisted selection of this gene in these backgrounds. The presence of other effective stripe rust resistance genes in cultivars Bolac and SQP Revenue in which Yr58-linked alleles were amplified did not allow us to perform a phenotypic assay to confirm the presence of this gene. Care should be taken to determine polymorphism of these markers among parents to be used for crossing.

Chhetri et al. (2016) concluded the presence of Yr46 in W195 based on genotyping with gene-based and linked markers. However, gene-based markers were not genotyped on the entire RIL population in that study. Comparison of phenotypic data of genotypes carrying Yr58 and Yr46 in combination and singly demonstrated their interaction in lowering stripe rust response under the controlled environment conditions (Table 4). Early expression of resistance (at the third leaf stage) was also noted among RILs carrying both genes under field conditions. In contrast, RILs possessing $\mathrm{Yr} 46$ and Yr58 singly expressed resistance at the fifth and fourth leaf stage, respectively. Similar enhancement of stem rust resistance was noted in a winter wheat line carrying stem rust resistance gene $\mathrm{Sr} 24$ and the pleiotropic locus Lr34/Yrl8/Sr57 (H. Bariana, unpublished data). Bariana et al. (1996) also reported the enhancement of stem rust resistance conditioned by ASR genes $\operatorname{Srl3}$ and $\mathrm{Sr} 30$ in the presence of adult plant resistance (APR) gene $\mathrm{Sr} 2$.

Australian cultivars Mace, Ventura, and Gladius were crossed with W195 to transfer Yr58 in these backgrounds. Single backcross $\mathrm{F}_{2}$ populations were planted during the 2014 crop season and selections were made under field conditions. Markers linked with $\mathrm{Yr} 46 / \mathrm{Lr} 67 / \mathrm{Sr} 55$ and $\mathrm{Yr} 58$ were genotyped on these selections and plants carrying combination of these genes have been selected. ASR and APR genes present in recurrent parents have also been selected using markers. The selected genotypes will impart triple rust resistance. The resultant material is being bulked up for distribution to wheat breeders for use as donor sources.

\section{ACKNOWLEDGMENTS}

The first author thanks the Australian Government for the Australian Leadership Award Fellowship to pursue Ph.D. studies at the University of Sydney and also acknowledges Government of Bhutan, Ministry of Agriculture and Forestry (MoAF) for granting study leave. Financial support from the GRDC Australia is gratefully acknowledged. We thank $\mathrm{K}$. Forrest for providing survey sequence data. 


\section{LITERATURE CITED}

Bansal, U. K., Hayden, M. J., Gill, M. B., and Bariana, H. S. 2010. Chromosomal location of an uncharacterised stripe rust resistance gene in wheat. Euphytica 171:121-127.

Bansal, U. K., Kazi, A. G., Singh, B., Hare, R. A., and Bariana, H. S. 2014a. Mapping of durable stripe rust resistance in a durum wheat cultivar Wollaroi. Mol. Breed. 33:51-59.

Bansal, U. K., Wicker, T., Keller, B., Hayden, M., and Bariana, H. S. 2014b. Molecular mapping of an adult plant stem rust resistance gene Sr56 in winter wheat cultivar Arina. Theor. Appl. Genet. 127:1441-1448.

Bariana, H. S., Bell, J. A., Brown, G. N., and Standen, G. E. 1996. A catalogue of the national cereal rusts control program (NCRCP) germplasm I: Wheat. Pages 137-140 in: Proc 8th Assembly of Wheat Breeding Society, Canberra, Australia.

Bariana, H. S., and McIntosh, R. A. 1993. Cytogenetic studies in wheat. XV. Location of rust resistance genes in VPM1 and their genetic linkage with other disease resistance genes in chromosome 2A. Genome 36:476-482.

Bariana, H. S., Parry, N., Barclay, I. R., Loughman, R., McLean, R. J., Shankar, M., Wilson, R. E., Willey, N. J., and Francki, M. 2006. Identification and characterization of stripe rust resistance gene $\operatorname{Yr} 34$ in common wheat. Theor. Appl. Genet. 112:1143-1148.

Chhetri, M., Bansal, U., Toor, A., Lagudah, E., and Bariana, H. 2016. Genomic regions conferring resistance to rust diseases of wheat in a W195/BTSS mapping population. Euphytica 209:637-649.

Dieguez, M. J., Pergolesi, M. F., Velasquez, S. M., Ingala, L., Lopez, M., Darino, M., Paux, E., Feuillet, C., and Sacco, F. 2014. Fine mapping of $L r S V 2$, a race sepcific adult plant leaf rust resistance gene on wheat chromosome 3BS. Theor. Appl. Genet. 127:1133-1141.

Forrest, K., Pujol, V., Bulli, P., Pumphery, M., Wellings, C., Herrera-Foessel, S., Huerta-Espino, J., Singh, R., Laguadah, E., Hayden, M., and Speilmeyer, W. 2014. Development of a SNP marker assay for the Lr67 gene of wheat using a genotyping by sequencing approach. Mol. Breed. 34:2109-2118.

Herrera-Foessel, S., Lagudah, E., Huerta-Espino, J., Hayden, M., Bariana, H., Singh, D., and Singh, R. 2011. New slow-rusting leaf rust and stripe rust resistance genes $\mathrm{Lr} 67$ and $\mathrm{Yr} 46$ in wheat are pleiotropic or closely linked. Theor. Appl. Genet. 122:239-249.

Kosambi, D. 1943. The estimation of map distances from recombination values. Ann. Eugen. 12:172-175.

Mago, R., Simkova, H., Brown-Guedira, G., Dreisigacker, S., Breen, J., Jin, Y., Singh, R., Appels, R., Lagudah, E. S., Ellis, J., Dolezel, J., and Spielmeyer, W. 2011. An accurate DNA marker assay for stem rust resistance gene $\mathrm{Sr} 2$ in wheat. Theor. Appl. Genet. 122:735-744.

Manly, K. F., Cudmore, R. H., Jr., and Meer, J. M. 2001. Map Manager QTX, cross-platform software for genetic mapping. Mamm. Genome 12: 930-932.
McIntosh, R. A., Wellings, C. R., and Park, R. F. 1995. Page 199 in: Wheat Rusts: An Atlas of Resistance Genes. CSIRO, Melbourne.

Murray, G. M., and Brennan, J. P. 2009. Page 69 in: The Current and Potential Costs from Diseases of Wheat in Australia. Grains Research and Development Corporation, Canberra.

O’Brien, L., Brown, J. S., Young, R. M., and Pascoe, I. 1980. Occurrence and distribution of wheat stripe rust in Victoria and susceptibility of commercial wheat cultivars. Australas. Plant Pathol. 9:14.

Randhawa, M., Bariana, H., Mago, R., and Bansal, U. 2015. Mapping of a new stripe rust resistance locus Yr57 on chromosome 3BS of wheat. Mol. Breed. 35:65.

Rozen, S., and Skaletsky, H. 1999. Primer3 on the WWW for general users and for biologist programmers. Pages 365-386 in: Bioinformatics Methods and Protocols. S. Misener and S. Krawetz, eds. Humana Press, Totowa, NJ.

Singh, R., Nelson, J., and Sorrells, M. 2000. Mapping Yr28 and other genes for resistance to stripe rust in wheat. Crop Sci. 40:1148-1155.

Somers, D., Isaac, P., and Edwards, K. 2004. A high-density microsatellite consensus map for bread wheat (Triticum aestivum L.). Theor. Appl. Genet. 109:1105-1114.

Spielmeyer, W., Sharp, P. J., and Lagudah, E. S. 2003. Identification and validation of markers linked to broad spectrum stem rust resistance gene Sr2 in wheat (Triticum aestivum L.). Crop Sci. 43:333-336.

Voorrips, R. E. 2002. MapChart: Software for the graphical presentation of linkage maps and QTLs. J. Hered. 93:77-78.

Wellings, C. R. 2007. Puccinia striiformis in Australia: a review of the incursion, evolution, and adaptation of stripe rust in the period 1979-2006. Aust. J. Agric. Res. 58:567-575.

Wellings, C. R., Wright, D. G., Keiper, F., and Loughman, R. 2003. First detection of wheat stripe rust in Western Australia: Evidence for a foreign incursion. Australas. Plant Pathol. 32:321-322.

Yang, J., Li, C., Gong, X., Gupta, S., Lance, R., Zhang, G., Loughman, R., and Zhu, J. 2011. Large mapping population with low markerdensity verse small population with high marker densityfor QTL mapping: A case study for mapping QTL controlling barley net blotch resistance. Pages 301-326 in: Proceedings of the 11th International Barley Genetics Symposium. G. Zhang, C. Li, and C. Liu, eds. Springer University Press, Zhejiang.

Zhao, L., Feng, J., Zhang, C. Y., Xu, X. D., Chen, X. M., Sun, Q., Miao, Q., $\mathrm{Xu}$, S. C., and Lin, F. 2012. The dissection and SSR mapping of a hightemperature adult-plant stripe rust resistance gene in American spring wheat cultivar Alturas. Eur. J. Plant Pathol. 134:281-288.

Zhou, X. L., Han, D. J., Gou, H. L., Wang, Q. L., Zeng, Q. D., Yuan, F. P., Zhan, G. M., Huang, L. L., and Kang, Z. S. 2014. Molecular mapping of a stripe rust resistance gene in wheat cultivar Wuhan 2. Euphytica 196: 251-259. 